\title{
ESTÁGIO SUPERVISIONADO E PRÁTICA REFLEXIVA: NARRATIVAS DE CONCLUINTES DA LICENCIATURA EM MATEMÁTICA (IFRN/MOSSORÓ)
}

\author{
F.C.S. SOUZA* e A. A. BORGES \\ Instituto Federal de Educação, Ciência e Tecnologia do Rio Grande do Norte \\ chagas.souza@ifrn.edu.br*
}

Artigo submetido em maio/2015 e aceito em dezembro/2015

DOI: $10.15628 /$ rbept.2016.3048

\section{RESUMO}

O estágio curricular supervisionado é um componente fundamental na formação docente, pois possibilita a relação entre teoria e prática, o contato com campo de trabalho, a aquisição dos conhecimentos pedagógicos e administrativos. Baseados nessa dimensão formativa do estágio, realizamos uma pesquisa cujo objetivo era conhecer como os alunos concluintes do curso de Licenciatura em Matemática do IFRN/Mossoró, em 2014, avaliam as experiências vividas nessa fase de sua formação. A metodologia constou de entrevistas abertas e gravadas em áudio com cinco alunos concluintes. Os entrevistados salientaram a importância do estágio para a sua formação profissional, visto que Ihes possibilitou um reencontro com a realidade escolar, dessa vez na condição de professores. As reflexões lhes permitiram um olhar para si próprios no intuito de se verem como seres cujas identidades estão em contínuo processo de construção.

PALAVRAS-CHAVE: Estágio Supervisionado, formação de professores, Licenciatura em Matemática.

\section{SUPERVISED AND REFLECTIVE PRACTICE: GRADUATING NARRATIVES OF DEGREE IN MATHEMATICS (IFRN/MOSSORÓ)}

\begin{abstract}
Supervised curriculum stage is a primordial element in teacher formation, cause allows the relationship between theory and practice, contact with field work, and pedagogical and administrative knowledge acquirement. Based in stage formation dimension, we perform a research which propose was know how graduating students of Mathematics from IFRN/Mossoró, 2014, assess own experiences in stage phase.
\end{abstract}

Metodology was performed through open and recorded interviews with five graduating students. Interviewed highlighted stage importance in their professional formation, due possibility of recover school reality, this time like teachers. The reflections allowed them look inside and see themselves like beings whose identities are in continuous construction process.

KEYWORDS: Supervised stage, Teachers formation, Graduation in Mathematics. 


\section{INTRODUÇÃO}

A literatura acadêmica na área de Educação, nas últimas décadas, tem se dedicado, dentre outros temas, às teorizações sobre a formação de professores. Nesses estudos, um tema recorrente é a Prática de Ensino sob a forma de Estágio Supervisionado, haja vista que os cursos de licenciatura precisam oferecer, além de conhecimentos teóricos, um período em que os licenciandos deverão, dentre outras coisas, articular a prática com a teoria que aprenderam durante a sua formação universitária. Entretanto, muitas vezes, o Estágio Supervisionado é percebido pelos alunos e professores como uma simples execução da prática profissional, destituída de contextualização ou abordagens teóricas (PICONEZ, 2012; PIMENTA, 2012; PIMENTA; LIMA, 2009).

No Instituto Federal de Educação, Ciência e Tecnologia do Rio Grande do Norte, Campus Mossoró, formou-se, no primeiro semestre de 2014, a primeira turma do curso de Licenciatura em Matemática. A discussão interna acerca do Estágio Supervisionado para a formação dos futuros professores nos levou a desenvolver uma pesquisa cujo objetivo era conhecer como os alunos da turma concluinte avaliavam essa etapa de sua formação. Em outros termos, procurávamos saber que reflexões esses alunos faziam sobre a sua formação após ter passado pelo estágio. Portanto, a pesquisa foi de cunho qualitativa e teve como método de recolha de dados entrevistas abertas com cinco licenciandos em Matemática que tinham concluído os seus estágios. As entrevistas foram gravadas, transcritas e submetidas à análise de conteúdo.

É importante destacar que o projeto pedagógico do curso de Licenciatura em Matemática foi aprovado em 2009, pela Resolução no 034/2009-CONSUP/IFRN (INSTITUTO..., 2009) e sua implantação tem relação com a criação, pelo governo federal, dos Institutos Federais (IFs), por meio da Lei no 11.892/08, a qual estabelece como um dos objetivos dessa instituição a criação de "cursos de licenciatura, bem como programas especiais de formação pedagógica, com vistas na formação de professores para a educação básica, sobretudo nas áreas de ciências e matemática, e para a educação profissional" (BRASIL, 2008a).

Este artigo está dividido em duas partes. Na primeira, realizamos uma síntese das considerações tecidas pelos pesquisadores no tocante ao Estágio Supervisionado. Em seguida, discutimos as reflexões feitas pelos alunos concluintes da Licenciatura em Matemática do IFRN/Mossoró a respeito das suas experiências durante essa etapa de formação acadêmica e profissional.

\section{O ESTÁGIO SUPERVISIONADO PARA ALÉM DA PRÁTICA DE ENSINO}

Antes de iniciarmos a nossa discussão, é importante conhecermos como o Estágio Curricular Supervisionado está presente na Lei no 11.788, de 25 de setembro de 2008, que dispõe sobre o estágio de estudantes:

Art. 1ํ Estágio é ato educativo escolar supervisionado, desenvolvido no ambiente de trabalho, que visa à preparação para o trabalho produtivo de educandos que estejam frequentando o ensino regular em instituições de educação superior, de educação profissional, de ensino médio, da educação especial e dos anos finais do ensino fundamental, na modalidade profissional da educação de jovens e adultos. 
$\S 1$ ㅇ O estágio faz parte do projeto pedagógico do curso, além de integrar o itinerário formativo do educando.

$\S 2$ o O estágio visa ao aprendizado de competências próprias da atividade profissional e à contextualização curricular, objetivando o desenvolvimento do educando para a vida cidadã e para o trabalho. (BRASIL, 2008a)

No que diz respeito aos alunos de licenciaturas, pode-se perceber, conforme a lei supracitada, que o Estágio Supervisionado é uma etapa necessária para o processo formativo docente, visto que ele não se restringe à simples transmissão de conteúdos, pelos estagiários, nas escolas em que ocorrem a prática de ensino. Dessa forma, o estágio deve ser um elo entre teoria e prática.

Apesar da sua dimensão formativa, na maioria das vezes o estágio é visto como de menor relevância se comparado às disciplinas teóricas. Isso se verifica na maioria das matrizes curriculares dos cursos de formação de professores, nas quais podemos evidenciar a desigualdade da carga horária destinada aos estágios e às demais disciplinas, como também o espaço e o tempo em que ocorrem. Uma vez que o estágio traz consigo a relação teoria-prática, ambas deveriam caminhar juntas já que, em um curso de formação de professores, a teoria não acontece dissociada da prática e vice-versa. O que ocorre na realidade é uma teoria no início dos cursos e uma prática colocada no final destes sob forma de Estágio Supervisionado (PIMENTA; LIMA, 2009).

Sobre essa discussão, Piconez (2012, p. 24) considera:

(...) nada de teoria no vazio; nada de empirismo desconexo. São duas obrigações de unidade que revelam a estreita e rigorosa síntese da teoria com a prática e que só se pode exprimir por sentido bidirecional, através da relação dialógica. Essa unidade situa-se no centro em que a teoria é determinada pelo conhecimento preciso da prática e no qual, em contrapartida, a teoria determina com mais rigor sua experiência.

No exercício de qualquer profissão é necessário utilizar técnicas para realizar determinadas ações. Mas habilidades não são suficientes para solução de problemas que os profissionais se deparam na sua rotina diária, o que gera uma compreensão dicotômica entre teoria e prática. Sobre isso, afirma Pimenta e Lima (2009, p. 37): “A prática pela prática e o emprego de técnicas sem a devida reflexão pode reforçar a ilusão de que há uma prática sem teoria ou de uma teoria desvinculada da prática". Para as autoras, as atividades do estágio ficam reduzidas "ao "como fazer', às técnicas a ser empregadas em sala de aula, ao desenvolvimento de habilidades específicas do manejo de classe, ao preenchimento de fichas de observação, diagramas, fluxogramas".

Atividades de microensino, oficinas pedagógicas, dinâmica de grupo exemplificam a perspectiva de estudo que é posta em um curso de formação de professores. No entendimento de Pimenta e Lima (2009), embora essas atividades sejam importantes, é necessário que o alunodocente, compreenda o processo de ensino como um todo.

O processo educativo é mais amplo, complexo e inclui situações específicas de treino, mas não pode a ele ser reduzido. Parece-nos que, a um certo nível, é possível falar em domínio de determinadas técnicas, instrumentos e recursos, para o desenvolvimento de determinadas habilidades em situação. Portanto, a 
habilidade que o professor deve desenvolver é a de saber lançar mão adequadamente das técnicas conforme as diversas e diferentes situações em que o ensino ocorre, o que necessariamente implica a criação de novas técnicas. (PIMENTA; LIMA, 2009, p. 38)

A simplificação excessiva dos estágios expõe as dificuldades e problemas na formação profissional do docente. A separação entre teoria e prática empobrece a prática docente nas escolas. Algumas vezes os professores não têm clareza sobre os objetivos que guiam suas ações no contexto escolar. Com isso, o papel das teorias é iluminar e oferecer instrumentos para análises que permitam questionar as práticas institucionalizadas. Pimenta e Lima (2009, p. 43), afirma que a prática educativa nos cursos de formação de professores deve "[...] possibilitar que os futuros professores compreendam a complexidade das práticas institucionais e das ações aí praticadas por seus profissionais como alternativa no preparo para sua inserção profissional".

A relação teoria e prática na formação docente nos remete a uma discussão sobre o tecnicismo na educação. Muitas vezes, um profissional é reconhecido como competente se ele está preocupado com problemas instrumentais, isso porque na perspectiva tecnicista, a competência profissional está relacionada à aplicação de teorias e técnicas para solucionar problemas instrumentais da prática profissional.

A formação docente pautada na racionalidade técnica tem como principal objetivo agregar instrumental técnico aos futuros professores para que estes, em momentos oportunos, apliquem na sua prática exemplos que os seus alunos deveriam seguir. De acordo com Monteiro (2002, p. 132):

Como o próprio nome revela, o objetivo dessa atividade era aprender a ensinar através da observação da "prática de ensino" bem sucedida de professores competentes e pela realização de atividades docentes onde o professor em formação realizava a "prática de ensino", ou seja, deveria demonstrar saber aplicar, da melhor forma possível, as diretrizes aprendidas anteriormente, produzindo de alguma forma, os modelos de aulas de professores bem sucedidos observados até então. A "prática" era para ser observada e reproduzida da melhor maneira possível.

Conforme Freire (1996), ao contrário de uma prática fechada e reprodutivista, é necessário uma prática docente crítica, ou seja, aquela que envolve o movimento dinâmico entre o fazer e o pensar sobre o fazer, o "pensar certo". Importa que o aprendiz de educador entenda que esse "pensar certo" não está em cartilhas e guias de professores e também não é uma produção ingênua de saber e pensar, muitas vezes decorrente de uma prática docente espontânea. Ao contrário, o pensar certo tem que superar a curiosidade ingênua através da reflexão sobre a prática a ponto de tornar-se crítica.

Para Freire (1996, p. 39) "é pensando criticamente a prática de hoje ou de ontem que se pode melhorar a próxima prática". Assim, a reflexão surge ligada à necessidade de resolver problemas que emergem durante a prática e à possibilidade de incertezas, havendo a necessidade de ter outras formas de resolução. Ela possibilita a revisão e construção de novas práticas e saberes, estes últimos vistos na perspectiva de Tardif (2012) como algo que não se restringe ao espaço acadêmico, mas numa pluralidade de tempos e espaços que acompanham a formação do educador. 


\section{ESTÁGIO SUPERVISIONADO COMO ESPAÇO DE REFLEXÃO}

Conforme já anunciamos, a pesquisa aqui apresentada teve o objetivo de conhecer como os alunos do curso de Licenciatura em Matemática do IFRN/Mossoró compreendem e avaliam o estágio supervisionado que realizaram no seu curso. Para tanto, adotamos um enfoque teóricometodológico qualitativo, visto que este possibilita a análise do objeto de estudo em suas dimensões subjetivas, em profundidade e extensão. Além disso, nossa intenção era trabalhar com outras fontes que estão além das estatísticas, daí o uso de entrevistas, as quais, segundo D’Ambrósio (2006, p. 16), “(...) são fundamentais e a observação de reações, facilitada pelos meios de registro só então disponíveis, como gravadores áudio e vídeo não é contemplada no modelo então dominante de tratamento estatístico".

Para Minayo (2009), a pesquisa qualitativa trabalha com o universo dos significados, dos motivos, das aspirações, das crenças dos valores e das atitudes. Esse conjunto de fenômenos humanos é entendido como parte da realidade social, pois o ser humano se distingue não só por agir, mas por pensar sobre o que faz e por interpretar suas ações dentro e a partir da realidade vivida e partilhada com seus semelhantes. Isso explica a nossa opção pelas narrativas dos alunos estagiários: consideramos que a utilização desse método na pesquisa sobre formação de professores nos leva à desconstrução e reconstrução das experiências, tanto do professor/pesquisador quanto dos sujeitos da pesquisa e/ou do ensino, caracterizando-se, portanto, como uma excelente oportunidade de autoformação (CUNHA, 1997; SOUZA, 2006; JOSSO, 2010).

Baseada nas considerações de Minayo, esta pesquisa passou por três etapas: a fase exploratória (definição do objeto da pesquisa, revisão de literatura), o trabalho de campo (entrevistas abertas com cinco alunos da turma concluinte) e a análise e tratamento do material empírico e documental (transcrição das entrevistas, a classificação e análise dos dados). É sobre essa última fase que tratamos a seguir.

Nos contatos com o licenciandos em Matemática, foram recolhidas várias informações sobre as suas experiências no Estágio Supervisionado. Entretanto, em função das limitações desse espaço, iremos nos restringir às suas reflexões sobre esse momento do seu curso de licenciatura. Para não quebrarmos a sequência das narrativas, preferimos apresentar a transcrição do núcleo central das entrevistas, para, em seguida, realizar a nossa discussão a respeito do conteúdo desses relatos. Importa ainda destacar que os nomes dos alunos são fictícios.

Narrativa do aluno estagiário Miguel:

[...] O estágio abriu as portas para uma vontade, talvez, que eu não tinha, que é ser professor. [...] Tirei muitas lições e vi que ser professor não é tão fácil. Exige muitas coisas de nós que estão para além dos muros da escola. E que a gente tem que ser muito profissional para levar essa profissão a sério. Eu defino o Estágio, para a formação do professor, como uma etapa essencial. Eu acho que é um momento onde a gente vai para sala de aula, colocar em prática toda aquela teoria que a gente absorveu dentro da sala de aula na graduação e nós somos levados a uma realidade, a um espaço onde a gente vai construindo nossas habilidades, vamos construindo melhor essa identidade. O Estágio, como etapa de formação, colabora muito no sentido de instruir, de formar, de proporcionar um espaço reflexivo também. Porque a medida que a gente está em sala de aula, ou em casa 
preparando um material ou estudando para dar aula, esse é o Estágio, o momento do Estágio. Então ele proporciona esse espaço. De como a gente está se tornando professor, de como a gente está vendo a profissão e dar possibilidades para pensar sobre o futuro, de pensar sobre o querer ser professor. [...] Tive que pesquisar, fui aos livros, fui à internet, pesquisei como é que pessoal lá fora elabora seus materiais, como planejam para eu poder elaborar os meus materiais dentro daqueles conteúdos.

Narrativa da aluna estagiária Ana:

[...] A partir do Estágio é que vamos identificar o que queremos para nossa sala de aula. Eu posso aplicar assim, eu posso fazer assim, eu posso aplicar dessa outra forma. A prática lúdica deveria ser mais concentrada, não como entretenimento, mas como uma forma de captar o aluno para sala de aula. [No Estágio] você sente se é aquilo que você quer. Principalmente quando você pega turmas diferenciadas da forma como eu peguei. Porque quando você pega uma turma padrão, toda com interesse, aí você olha e diz: "ah, é isso que eu quero!" E quando você pega um turma que ela é mais distinta, aí você diz assim: "rapaz, se for isso aqui, não é interessante para mim não!".

Narrativa da aluna estagiária Juliana:

[...] O Estágio foi para eu ver o que eu posso, o que eu vou mudar ou não vou mudar se futuramente eu for dar aula. [...] O Estágio é de fundamental importância. É porta para que a gente vá seguir a profissão. [...] O Estágio é um ensaio da nossa futura profissão. Não vou dizer que vou levar só coisas boas, porque nem tudo é bom. Mas o que eu não fiz, eu vou fazer na minha sala, como, por exemplo, os planos de aula, que eu acho que é o principal.

Narrativa do aluno estagiário Heitor:

[...]A gente iniciou com o Estágio Supervisionado em sala de aula acompanhando o professor, basicamente, e eu tive a oportunidade de estagiar em algumas escolas em que eu aprendi bastante. [...] Eu, particularmente, entrei em sala de aula, avaliei o professor, e eu pensei que sabia dar mais aula do que ele. Mas na realidade é diferente. Cada caso é um caso. Eu comecei a conversar com os alunos e cada aluno tem uma particularidade diferente. Eles têm um pensamento, esses pensamentos formam o conjunto, e aí o difícil é você trabalhar com esse conjunto. [Quanto aos professores] A gente costuma se espelhar nos melhores. É uma boa estratégia para se dar bem. Pronto, o professor que dá a aula: a gente olha, observa e pensa "rapaz, esse professor tem a letra bonita, organiza o quadro, é um professor que tem postura em sala de aula, sabe se comunicar com o aluno e eu vou querer ser um professor igual a ele". Isso para a maioria dos alunos de Licenciatura, isso aí é habilidade, você vai ter que adquirir a habilidade que ele adquiriu.

Narrativa do aluno estagiário José Roberto:

[...] tinha pra mim que eu teria uma grande dificuldade em estar na frente da sala de aula. Mas antes de começar o Estágio III, que é a regência de sala, eu participei de um Estágio remunerado pelo Estado. E foi através desse Estágio quando aconteceu a minha desenvoltura. [...] eu não tive essa dificuldade que os 
estudantes de Licenciatura têm, que é esse medo de falar em público, de lidar com os alunos, de falar com a sala cheia, que está diretamente voltada pra você já que o professor é o centro da atenção. Então eu não tive muita dificuldade. É lógico que me ajudou, já que o Estágio que tinha participado antes eu era como se fosse uma cobaia e, quando chegou no Estágio III, eu estava muito além da capacidade. [...] o Estágio, a meu ver, é importante pois traz o primeiro contato com o aluno de Licenciatura, com a sala de aula, com a realidade que ele vai enfrentar. Tanto trabalhando no estado como no município já que o Estágio Supervisionado proporciona isso e a relação direta que a gente tem com os alunos. As vezes, uma relação pacífica, as vezes nem tanto. Mas, no geral, tem importância significativa para a docência. [...] o Estágio me ajudou a ver a carreira docente de forma diferente, até porque quem está de fora, quem não está na prática vê de uma maneira totalmente diferente de quando ela passa a participar ativamente daquela carreira. É lógico que vai mudar seu ponto de vista. [...] Se a pessoa quiser ser professor, se a pessoa quiser ter somente o curso superior não precisa passar pelas quatro etapas de Estágio. Mas se quiser, realmente, seguir a carreira docente porque a experiência e as virtudes que a pessoa ganha com esse Estágio são muito compensatórias.

Nos discursos dos alunos entrevistados, o Estágio Supervisionado é visto, de forma implícita ou explícita, como uma etapa que propicia aos futuros professores uma reflexão sobre práticas de ensino, além de oferecer situações que os conduzem à criação e/ou aperfeiçoamento de novas habilidades de cunho pedagógico.

A reflexão sobre a prática profissional tem obtido grande interesse acadêmico. Grande parte desses estudos tem como base as considerações de Schön (2000), o qual propõe uma nova epistemologia da prática, expressa no que denominou de "reflexão-na-ação". Para ele, quando aprendemos a fazer algo, tornamo-nos aptos a realizar aquela tarefa sem pensar antes de executála. Entretanto, a reflexão potencializa melhorias nas práticas acadêmica e profissional. Ela é aconselhável para que não transformemos as nossas ações em os atos descontextualizados, mecânicos, automáticos e rotineiros.

Nosso ato espontâneo de conhecer-na-ação geralmente nos permite dar conta de nossas tarefas. No entanto, nem sempre é assim. Uma rotina comum produz um resultado inesperado, um erro teima em resistir à correção, ou, ainda que ações comuns produzam resultados comuns, há algo nelas que parece estranho, porque passamos a vê-las de uma outra maneira. Todas essas experiências, agradáveis e desagradáveis, contém um elemento de surpresa". (SCHÖN, 2000, p. 32, grifo do autor)

É na perspectiva do professor reflexivo que devemos compreender os comentários dos alunos entrevistados. Os estagiários Juliana e Miguel, ao comentarem sobre as suas trajetórias durante o estágio, destacam a importância do planejamento. Juliana deixa entender que a ausência do plano de aula durante estágio foi prejudicial à sua prática. Ela percebe agora a necessidade do professor planejar antes de entrar em sala de aula. Já Miguel tomou os planos de aula e de ensino como momentos de reflexão, levando-o a buscar outros meios que o ajudassem no desenvolvimento do seu estágio.

O valor dado por ambos ao planejamento, fato que talvez não ocorrido durante as disciplinas pedagógicas, evidencia uma autoavaliação que esses graduandos fazem de seu processo 
formativo. Agora, mais do que antes, eles compreendem o planejamento não como uma ação "pro forma", mas como "um processo de racionalização, organização e coordenação da ação docente, articulando a atividade escolar e a problemática do contexto social (LIBÂNEO, 1994, p. 222).

Também elucidativa é a importância que teve o Estágio Supervisionado para a decisão de seguir ou não a carreira docente. Isso fica patente nas palavras dos alunos Miguel ("o estágio abriu as portas para uma vontade, talvez, que eu não tinha, que é ser professor"), Ana ("você sente se é aquilo que você quer"), Juliana ("é a porta para que a gente vá seguir a profissão") e José Roberto ("me ajudou a ver a carreira docente de forma diferente").

Poderíamos nos surpreender com essas dúvidas e indecisões quanto à docência por supormos, à primeira vista, que alguém estuda em um curso de licenciatura movido pelo desejo de ser professor. Entretanto, isso não ocorre de fato. Os resultados de uma pesquisa realizada por Souza e Nascimento, em 2011, com alunos dessa primeira turma da Licenciatura em Matemática do IFRN/Mossoró deixam claro que a entrada de muitos deles nesse curso não ocorreu de forma tranquila. Diante da desvalorização social dada à docência, a matrícula na licenciatura em Matemática só ocorreu depois de algumas tentativas, sem êxito, de seguir áreas mais valorizadas como as Engenharias e Direito. Esse fato também explica a grande evasão de alunos matriculados em licenciaturas, como é o caso dessa turma que estamos ora tratando.

Também o estágio evidenciou a realidade do cotidiano escolar, agora na perspectiva de quem estava desempenhando o papel de um profissional da educação. Isso explica o porquê de frases como: "Tirei muitas lições e vi que ser professor não é tão fácil”, "turmas diferenciadas", "a realidade é diferente", "quem não está na prática vê de uma maneira totalmente diferente de quando ela passa a participar ativamente daquela carreira". As constatações desses alunos demonstram a ausência ou pouca frequência de uma discussão dos problemas presentes na prática docente e no cotidiano escolar ao longo do curso de licenciatura. Muitas vezes, na academia, são pensadas soluções ideais para situações que, na realidade prática, são muito complexas e não podem ser resolvidas com decisões simples. Daí o "choque de realidade" quando estes profissionais iniciam a sua prática, levando muitos a não seguir em frente ou, caso sigam, sejam vítimas, mais tarde, do mal-estar docente, um problema muito bem analisado por Zaragoza (1999).

Apesar da abertura para a reflexão e a autocrítica, os discursos dos entrevistados também evidenciam a reprodução de ideias conservadoras. O estagiário José Roberto afirma que, na sala de aula, o professor é o centro das atenções. Ou seja, o aluno e futuro professor, mantem na sua concepção, um pensamento considerado hoje equivocado no que diz respeito à relação professoraluno e ensino-aprendizagem. Suas ideias mais se aproximam do que Paulo Freire chamou de "educação bancária", na qual o papel do professor é:

[...] "encher" os alunos do conteúdo da narração, conteúdo alheio à realidade, separado da totalidade que a gerou e poderia dar-lhe sentido. Assim, a educação passa a ser "o ato de depositar", no qual os alunos são os depósitos e o professor aquele que deposita. Em lugar de comunicar, o professor dá comunicados que os alunos recebem pacientemente, aprendem e repetem. É a concepção "acumulativa" da educação (concepção bancária). Na concepção bancária da educação, o conhecimento é um dom concedido por aqueles que se consideram como seus possuidores àqueles que eles consideram que nada sabem. Projetar uma ignorância absoluta sobre os outros é característica de uma ideologia de opressão. É uma negação da educação é do conhecimento como processo de 
procura. O professor apresenta-se a seus alunos como seu "contrário" necessário: considerando que a ignorância deles é absoluta, justifica sua própria existência. Os alunos, alienados como o escravo na dialética hegeliana, aceitam sua ignorância como justificativa para a existência do professor, mas diferentemente do escravo, jamais descobrem que eles educam o professor (FREIRE, 1979, p. 41).

Ao contrário da concepção fixista e imobilista da educação bancária, Freire defende uma educação problematizadora, por esta reconhecer o caráter histórico e a historicidade dos homens. Esta educação reconhece os homens como "seres que estão sendo, como seres inacabados, inconclusos em e com uma realidade que, sendo histórica também, é igualmente inacabada" (2012, p. 80, grifos do autor).

O homem é um ser que se reconhece inacabado, inconcluso. É isso que percebemos nos relatos dos estagiários: a necessidade de construir-se enquanto profissionais da educação. As reflexões que fazem sobre a experiência vivida nos levam a considerar o Estágio Supervisionado como uma etapa fundamental no desenvolvimento profissional docente, entendido aqui como "processo que se vai construindo à medida que os docentes ganham experiência, sabedoria e consciência profissional" (MARCELO, 2009, p. 11).

O desenvolvimento profissional do professor pode ser concebido como "qualquer intenção sistemática de melhorar a prática profissional, crenças e conhecimentos profissionais, com o objetivo de aumentar a qualidade docente, de pesquisa e de gestão (IMBERNÓN, 2011, p. 47). É, portanto, um conceito que considera a capacidade criativa e reflexiva do docente durante 0 desempenho de suas tarefas. A escola é vista não como um ambiente de transmissão de modelos, mas como um espaço de criação, de colaboração e de reflexão. Por isso, Marcelo $(2009$, p. 15) assegura que "desenvolvimento profissional e processos de mudança são variáveis intrinsecamente unidas. O desenvolvimento profissional procura promover a mudança junto dos professores, para que estes possam crescer enquanto profissionais - e também como pessoas".

É a busca "para se dar bem" na profissão que leva alguns a "se espelhar nos melhores professores", como afirma o aluno estagiário Heitor. A reprodução de modelos, a partir do que ele considera válido levar para sala de aula, embora não seja a melhor forma de se aperfeiçoar na profissão, é tema recorrente na literatura que trata da docência dos professores no início da carreira. Pimenta e Lima (2006, p. 35), por exemplo, alertam para os riscos dessa prática:

Em que pese a importância dessa forma de aprender, ela não é suficiente e apresenta alguns limites. Nem sempre o aluno dispõe de elementos para essa ponderação crítica e apenas tenta transpor os modelos em situações para as quais não são adequados. Por outro lado, o conceito de bom professor é polissêmico, passível de interpretações diferentes e mesmo divergentes.

Ainda para as autoras, a imitação de modelos "gera o conformismo, é conservadora de hábitos, ideias, valores, comportamentos pessoais e sociais legitimados pela cultura institucional dominante" (PIMENTA; LIMA, 2009, p. 35). Por isso, entendemos que na formação de professores é fundamental que ocorra cotidianamente uma reflexão crítica sobre a prática e sobre suas ações, pois as ações de hoje analisadas criticamente podem melhorar as de amanhã. Não podemos trabalhar a partir de modelos ou da elaboração desses modelos, haja vista que o trabalho se faz no exercício contínuo de sua função e as situações não podem ser previstas e acabadas, o que exige habilidade e improvisação do sujeito. 


\section{CONSIDERAÇÕES FINAIS}

Não é demais reforçar que o Estágio Supervisionado é elemento essencial na formação docente por não só possibilitar a relação entre teoria e a prática, mas também o contato com campo de trabalho, a aquisição dos conhecimentos pedagógicos, administrativos, dentre outros.

Nesta pesquisa, colocamos em discussão as reflexões que alguns alunos do último período do curso de Licenciatura Plena em Matemática do IFRN/Mossoró fizeram acerca das suas experiências durante estágio curricular supervisionado. A nossa intenção era trazer para o debate a importância dessa etapa do curso de Licenciatura para o desenvolvimento profissional desses alunos e possibilitar, por meio das narrativas de si, momentos de reflexão sobre essa etapa da sua formação superior. Por meio de entrevistas abertas, os alunos relataram as suas experiências, olharam para si e puderam avaliar o seu curso, as suas ações e projetar o seu futuro profissional.

Com base no exposto, podemos afirmar que a reflexão sobre as experiências permite um caminhar para o nosso interior com o intuito de confrontar o que almejamos e o que temos realizado profissionalmente. Essa iniciativa provocará inevitavelmente um conflito, uma avaliação sobre nossas ações para conosco e para os outros. Certamente, a partir desse conflito, iremos ao encontro de soluções, ou seja, desencadearemos um processo de mudança. É isso que se verifica na reflexão-na-ação. É isso que esperamos que o Estágio Supervisionado tenha sido capaz de gerar nesses primeiros professores de Matemática formados pelo IFRN, Campus Mossoró.

\section{REFERÊNCIAS}

1. BRASIL. Lei $\mathrm{n}^{\circ}$. 11.892, de 29 de dezembro de 2008. Institui a Rede Federal de Educação Profissional, Científica e Tecnológica, cria os Institutos Federais de Educação, Ciência e Tecnologia, e dá outras providências. Diário Oficial da União, Brasília, p.1, 29 dez. 2008a. Disponível em: <https://www.planalto.gov.br/ccivil_03/_ato2007-2010/2008/lei/l11892 .htm> Acesso em: 10 jan. 2014.

2. BRASIL. Lei n. 11.788 , de 24 de setembro de 2008. Dispõe sobre o estágio de estudantes. Diário Oficial da União, Brasília, p. 129, 30 out. 2008b. Disponível em: <https://www.planal to.gov.br/ccivil_03/_ato2007-2010/2008/lei//11788.htm> Acesso: em 23 jan. 2014.

3. CUNHA, Maria Isabel. CONTE-ME AGORA! As narrativas como alternativas pedagógicas na pesquisa e no ensino. Revista da Faculdade de Educação. São Paulo, v. 23, n. 1-2, jan./dez. 1997. Disponível em: <http://dx.doi.org/10.1590/S0102-25551997000100010> Acesso em: 22 jan. 2014.

4. D’AMBROSIO, Ubiratan. Prefácio. In: BORBA, Marcelo de C.; ARAÚJO, Jussara L. (Orgs.) Pesquisa qualitativa em Educação Matemática. 2. ed. Belo Horizonte: Autêntica, 2006. p. 1121.

5. FREIRE, Paulo. Conscientização: teoria e prática da libertação - uma introdução ao pensamento de Paulo Freire. São Paulo: Cortez \& Moraes, 1979.

6. Pedagogia do oprimido. Rio de Janeiro: Nova Fronteira, 2012.

7. Pedagogia da autonomia. 37. ed. São Paulo: Paz e Terra, 1996.

8. IMBERNÓN, Francisco. Formação docente e profissional. 9. ed. São Paulo: Cortez, 2011. 
9. INSTITUTO FEDERAL DE EDUCAÇÃO CIÊNCIA E TECNOLOGIA DO RIO GRANDE DO NORTE. Projeto Pedagógico do Curso Superior de Licenciatura Plena em Matemática. Natal, 2009. Disponível em: <http://portal.ifrn.edu.br/ensino/cursos/cursos-de-graduacao/licenciatura/li cenciatura-plena-em-matematica/at_download/coursePlanPrev> Acesso em: 22 jan. 2014.

10. JOSSO, Marie-Christine. Experiências de vida e formação. São Paulo/Natal: Paulus/EDUFRN, 2010.

11. LIBÂNEO, José Carlos. Didática. São Paulo: Cortez, 2004

12. MARCELO, Carlos. Desenvolvimento Profissional Docente: passado e futuro. Sísifo, Lisboa, n. 8, p. 7-22, jan./abr. 2009.

13. MONTEIRO, Ana Maria. A prática de ensino e a produção de saberes na escola. In CANDAU, Vera Maria (Org.). Didática, currículo e saberes escolares. 2. ed. Rio de Janeiro: DP\&A, 2002. p. $129-147$.

14. PICONEZ, Stela C. Bertholo. Prática de ensino e o estágio supervisionado: a aproximação da realidade escolar e a prática da reflexão. In: (Coord.). A prática de ensino e o estágio supervisionado. 24. ed., Campinas: Papirus, 2012. p. 13-33.

15. PIMENTA, Selma Garrido. O estágio na formação de professores: unidade teoria e prática? 11. ed. São Paulo: Cortez, 2012.

16. PIMENTA, Selma Garrido; LIMA, Maria Socorro L. Estágio e docência. 4. ed. São Paulo: Cortez, 2009.

17. SCHÖN. Donald A. Educando o profissional reflexivo: um novo design para o ensino aprendizagem. Porto Alegre: Artmed, 2000.

18. SOUZA, Elizeu C. O conhecimento de si: estágio e narrativas de formação de professores. Rio de Janeiro: DP\&A; Salvador: UNEB, 2006.

19. SOUZA, Francisco das Chagas S.; NASCIMENTO, Augusto Sávio G. Escritos e reflexões sobre si: uma experiência de autoformação com licenciandos em Matemática do IFRN/Mossoró. In: COLÓQUIO INTERNACIONAL EDUCAÇÃO E CONTEMPORANEIDADE, 5., 2011, São Cristóvão-SE. Anais... Universidade Federal do Sergipe, 2011.

20. TARDIF, Maurice. Saberes docentes e formação profissional. 12. ed. Petrópolis: Vozes, 2012.

21. ZARAGOZA, José Manuel Esteve. O mal-estar docente: a sala de aula e a saúde dos professores. Bauru-SP: EDUSC, 1999. 